\title{
EL COBRE COMO PALANCA DE DESARROLLO PARA CHILE*
}

\author{
José Pablo Arellano M. \\ Cieplan
}

\begin{abstract}
Resumen: El cobre ha sido clave y lo sigue siendo para el desarrollo de Chile. En este artículo se sostiene que su potencial contribución al desarrollo es mucho mayor y que no está siendo aprovechada. Se explica por qué y se reflexiona sobre cómo lograr esa mayor contribución del cobre y de la minería al desarrollo del país. Después de revisar su impacto tradicional al PIB, presupuesto fiscal y exportaciones, se examina su aporte
\end{abstract}

José Pablo Arellano. Ph.D. en economía, Harvard University. Economista de Cieplan y profesor titular de la Universidad de Chile. Presidente ejecutivo de Codelco (2006-2010), Director Nacional de Presupuestos (1990-1996) y Ministro de Educación (1996-2000). Dirección electrónica: josepablo.arellano@ cieplan.org.

* Parte de este documento recoge experiencias del autor como Presidente Ejecutivo de Codelco. Agradezco especialmente a Enrique Silva, quien fue un gran colaborador en varias presentaciones sobre estas materias. Agradezco los comentarios de Jorge Bande, Diego Hernández, Patricio Meller, Marco Orellana, Gonzalo Rivas, Osvaldo Urzúa, Iván Valenzuela, Joaquín Vial, de los participantes en el Seminario de Cieplan el 19 de mayo del 2011 y de dos árbitros anónimos de Estudios Públicos. Este trabajo es parte del programa de investigaciones de Cieplan. 
potencial aprovechando la participación chilena del mercado mundial y sus perspectivas.

Se estudia el impacto multiplicador del cobre y se discute cómo acentuarlo y acelerar su contribución al desarrollo. Se revisan en particular los temas de recursos humanos y desarrollo tecnológico.

Palabras clave: minería, desarrollo, cluster, Chile.

Recibido: noviembre 2011; aceptado: marzo 2012.

\section{COPPER: AN ENGINE FOR CHILE'S DEVELOPMENT}

Abstract: Copper has been and continues to be key to Chile's development. In this article it is held that it has a greater potential to contribute to development and that potential is not being exploited. It explains why and reflects on how to attain that greater contribution by copper and by mining to the country's development. After reviewing its traditional impact on the GDP, the fiscal budget and exports, the article examines its potential contribution by taking advantage of Chile's share of the world market and its future outlook.

Keywords: mining, development, cluster, Chile.

Received: November 2011; accepted: March 2012.

Que el cobre ha sido clave para el desarrollo de Chile está fuera de discusión. En este artículo se propone destacar que su potencial contribución al desarrollo es mucho mayor y que no está siendo totalmente aprovechado. El artículo explica por qué no se está aprovechando todo el potencial y examina cómo lograr una mayor contribución del cobre y de la minería al desarrollo del país. El artículo quiere aportar a una reflexión principalmente en los ambientes externos a la minería en los cuales no se aprecia en toda su dimensión la importancia y potencial contribución del sector al desarrollo del país.

En una primera sección se revisa el aporte tradicional del cobre al desarrollo chileno. En la segunda se examina la forma en que la política macroeconómica ha logrado controlar los impactos negativos de la volatilidad característica de los precios del cobre. En la tercera se pone de relieve la importancia que ha adquirido la participación de Chile en el mercado mundial. La cuarta sección revisa brevemente las proyec- 
ciones del mercado internacional. Con las oportunidades que se derivan de las perspectivas de mercado y de la participación de mercado en este escenario de mayor estabilidad fruto de la política macroeconómica, en la sección cinco se estudia cómo elevar el efecto multiplicador en el desarrollo de esta industria. Las dos secciones siguientes repasan temas críticos con ese propósito: disponibilidad de recursos humanos calificados, la innovación, investigación y desarrollo. Se concluye con unas consideraciones finales.

\section{El aporte tradicional del cobre al desarrollo chileno}

El principal aporte directo del cobre al desarrollo ha sido como fuente de divisas provenientes de la exportación junto a su aporte a los ingresos del Estado. Su contribución directa al empleo e incluso al PIB ha sido mucho más limitada. El Cuadro $\mathrm{N}^{\circ} 1$ muestra la contribución al PIB y al empleo. Apenas 50.000 trabajadores es el empleo directo de las empresas mineras de cobre, esto es, menos del $0,8 \%$ del empleo nacional. Cabría agregar el número de trabajadores de empresas contratistas que se desempeñan en las faenas mineras, con lo cual el total de trabajadores en el sector llega a unos 180.000, pero aun así la contribución al empleo total es baja. El aporte promedio al PIB de los últimos 30 años, medido a precios constantes del 2003, llega a 6,2\%, alcanzando al $7 \%$ de manera excepcional en dos años. La minería en su conjunto contribuyó al 7,9\% del PIB en las últimas tres décadas. Con el alza reciente de precios de los commodities la contribución es mucho mayor. Medida a precios del año 2008, la contribución del cobre al PIB en los últimos seis años (2006-2011) se eleva al 12,7\% y la de la minería al $14 \%{ }^{1}$.

En materia fiscal en cambio, como se ve en el Cuadro $\mathrm{N}^{\mathrm{o}} 2$, el aporte de Codelco en los últimos 20 años fue equivalente al 13\% de los ingresos tributarios, superando en algunos años el 30\%. Si se suma la tributación de la gran minería privada, el total de aportes llegó a un récord equivalente al $46 \%$ de los ingresos tributarios totales el año 2007.

${ }^{1}$ A precios del 2003 el promedio es de menos de la mitad, 5,5\% y 6,7\% del PIB respectivamente. 
CUADRO No N $^{\circ} \quad$ CONTRIBUCIÓN DE LA MINERÍA DEL COBRE AL PRODUCTO INTERNO BRUTO Y AL EMPLEO, 1980-2009 (en \%)

\begin{tabular}{lccc}
\hline Año & $\begin{array}{c}\text { Contribución minería } \\
\text { al PIB } \\
\text { (en pesos constantes } \\
\text { de 2003) }\end{array}$ & $\begin{array}{c}\text { Contribución cobre } \\
\text { al PIB } \\
\text { (en pesos constantes } \\
\text { de 2003) }\end{array}$ & $\begin{array}{c}\text { Empleo directo } \\
\text { en la minería } \\
\text { del cobre } \\
\text { (miles de trabajadores) }\end{array}$ \\
\hline 1980 & 7,1 & 3,5 & \\
1990 & 7,7 & 5,0 & 44,9 \\
2000 & 8,7 & 7,2 & 46,2 \\
2002 & 8,3 & 6,9 & 33,6 \\
2004 & 8,5 & 7,0 & 34,9 \\
2008 & 6,7 & 5,5 & 37,0 \\
2009 & 6,7 & 5,5 & 50,3 \\
\hline
\end{tabular}

Fuentes: Codelco y Banco Central de Chile, Meller (2002).

CUADRO No ${ }^{\circ}: \quad$ APORTE DE CODELCO AL FISCO COMO PORCENTAJE DE LA RECAUDACIÓN TRIBUTARIA TOTAL

\begin{tabular}{lc}
\hline Año & Aporte Codelco en \% \\
\hline & \\
1990 & 34,2 \\
1991 & 15,1 \\
1992 & 12,3 \\
1993 & 5,2 \\
1994 & 9,6 \\
1995 & 15,6 \\
1996 & 8,3 \\
1997 & 8,7 \\
1998 & 2,7 \\
1999 & 2,3 \\
2000 & 5,7 \\
2001 & 3,3 \\
2002 & 2,9 \\
2003 & 6,3 \\
2004 & 20,1 \\
2005 & 22,2 \\
2006 & 33,4 \\
2007 & 25,6 \\
2008 & 21,6 \\
2009 & 12,8 \\
2010 & 15,0 \\
Promedio & 13,5 \\
\end{tabular}

Fuente: Dipres (Dirección de Presupuesto, Ministerio de Hacienda, Chile). 
La participación del cobre en las exportaciones en los últimos 20 años, en promedio, superó el $42 \%$, llegando en algunos años al $56 \%$ (Cuadro $\mathrm{N}^{\mathrm{o}} 3$ ). Durante los años 60 y 70 la significación del cobre en las exportaciones y en los ingresos fiscales fue incluso mayor ${ }^{2}$.

\section{CUADRO N ${ }^{\circ}$ 3: $\quad$ PARTICIPACIÓN DEL COBRE EN EL TOTAL DE EXPORTACIONES}

\begin{tabular}{lccc}
\hline Año & $\begin{array}{c}\text { Exportaciones } \\
\text { de cobre } \\
\text { (millones de USS\$) }\end{array}$ & $\begin{array}{c}\text { Participación del } \\
\text { cobre en exportaciones } \\
\text { totales (\%) }\end{array}$ & $\begin{array}{c}\text { Exportaciones } \\
\text { de cobre } \\
\text { (millones de US\$ 2009) }\end{array}$ \\
\hline $1960-1965$ & 348 & 65 & 1.790 \\
$1966-1970$ & 740 & 75 & 3.442 \\
$1971-1975$ & 972 & 71 & 3.482 \\
$1976-1980$ & 1.525 & 51 & 3.596 \\
$1981-1985$ & 1.738 & 46 & 2.965 \\
$1986-1990$ & 3.048 & 46 & 4.737 \\
$1991-1995$ & 4.296 & 38 & 5.932 \\
$1996-2000$ & 6.237 & 36 & 8.085 \\
2000 & 7.284 & 38 & 10.408 \\
2001 & 6.537 & 36 & 9.235 \\
2002 & 6.323 & 35 & 9.145 \\
2003 & 7.815 & 36 & 10.730 \\
2004 & 14.723 & 45 & 19.028 \\
2005 & 18.965 & 46 & 22.845 \\
2006 & 32.710 & 56 & 37.655 \\
2007 & 37.778 & 56 & 39.139 \\
2008 & 32.894 & 49 & 32.040 \\
2009 & 27.454 & 51 & 27.454 \\
2010 & 39.290 & 56 & 37.695 \\
& & & \\
\hline
\end{tabular}

Fuente: Banco Central de Chile.

Mientras más escasas han sido las divisas y más restrictiva la situación de financiamiento del Estado, más relevante ha sido la contribución del cobre a la economía chilena.

La influencia indirecta de la minería del cobre es bastante mayor, como veremos más adelante.

${ }^{2}$ Un buen análisis de la importancia del cobre para el desarrollo del país en esas décadas puede verse en Ffrench Davis y Tironi (1974) y en el capítulo "El cobre chileno y la política minera" de Meller (2002). 
A pesar de su gran importancia, el aporte del cobre al desarrollo se ha visto disminuido, e incluso muchas veces se ha considerado causa de grandes dificultades, porque los ciclos del precio históricamente impactaron en forma negativa la economía generando inestabilidad macroeconómica e inseguridad cambiaria. Ello hacía más difícil el surgimiento de otras exportaciones y contribuyó a la inestabilidad en el empleo y a la inflación. Afortunadamente y a pesar de la volatilidad de los precios del cobre, en los últimos 20 años esta inestabilidad se ha atenuado, gracias a un nuevo esquema de políticas que se describe a continuación.

\section{La administración de los ciclos de precios del cobre}

El Grafico No 1 muestra los precios del cobre en la Bolsa de Londres, revelando su conocida volatilidad.

Ello tiene fuerte impacto en los aportes del sector tanto en divisas como al fisco. Los aportes de Codelco al fisco fluctuaron en los últimos 20 años entre el 2,3\% y el 34\% de los ingresos tributarios. Lo tradicional era que con precios altos el Estado aumentaba sus gastos, los que, cuando bajaban los precios del cobre y los ingresos fiscales, eran muy difíciles de disminuir, generando déficits presupuestarios. A partir de 1987 se estableció un fondo de estabilización del cobre, que poste-

GRÁFICO No 1 : PRECIOS HISTÓRICOS DEL COBRE EN CENTAVOS DE DÓLAR POR LIBRA, C/LB 2010, 1908-2010

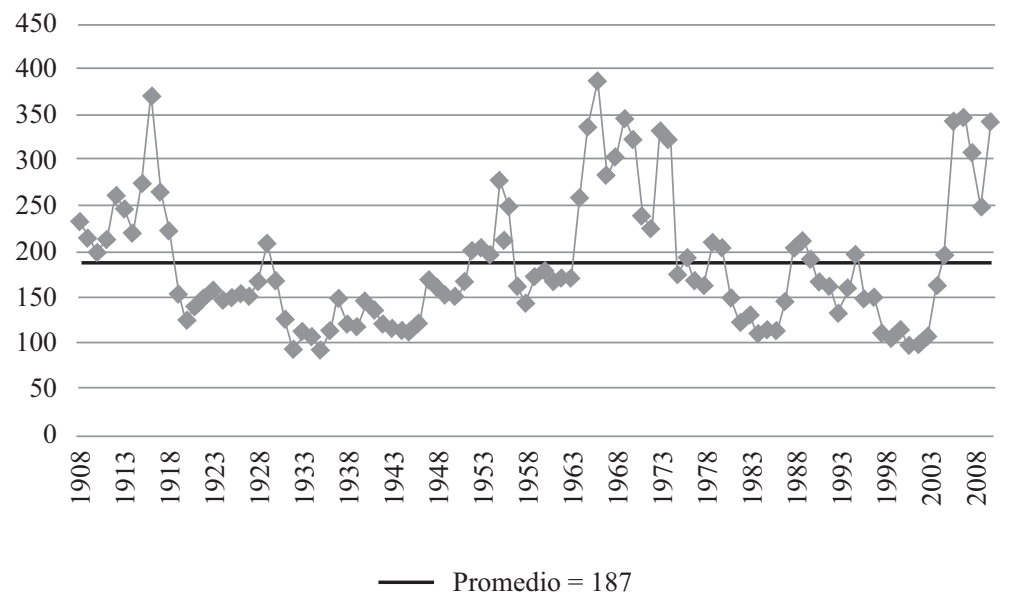

Fuente: Codelco. 
riormente se amplió al molibdeno, como parte de la política de balance estructural. El gasto del Estado, de acuerdo a esta política, se ajusta a los precios del cobre de largo plazo $^{3}$. Esta nueva política fiscal sumada a una política de tipo de cambio flexible, con una política monetaria que apunta a una meta de inflación, se ha traducido en un escenario de política macroeconómica que estabiliza los ciclos externos originados en el precio del cobre. Este nuevo esquema no solo ha atenuado el impacto interno de los ciclos de precios del cobre, sino que además ha permitido hacer política contracíclicas.

A costa de las crisis anteriores, el país ha aprendido, se han creado consensos y se ha dado una institucionalidad para lograr mitigar el impacto de la volatilidad. Es un avance significativo que se puso a prueba con muy buenos resultados en la última crisis financiera internacional ${ }^{4}$. También, pasó bien la prueba de la crisis asiática de fines de los 90, no en materia cambiaria, pero sí en materia fiscal.

Esta nueva realidad hace que el impacto del cobre sobre el desarrollo sea mucho mayor ya que las crisis provocadas por la volatilidad de su precio se han controlado de manera significativa ${ }^{5}$. Sin embargo, ha sido más fácil reducir el impacto de la volatilidad de los precios del cobre en el presupuesto fiscal que en la competitividad del resto de la producción de transables, tanto exportaciones como sustitutos de importación. Los transables ven afectada su rentabilidad con la apreciación cambiaria resultante de las bonanzas del precio del cobre. Esto, por cierto, es especialmente relevante para los productores de menor rentabilidad. Con todo, la menor volatilidad del tipo de cambio es muy importante para la diversificación exportadora, ya que una inestabilidad cambiaria, especialmente en periodos de apreciación cambiaria pronunciada, puede sacar del mercado o al menos impedir seguir ganando en escala y participación de mercado, y con ello dificultar el desarrollo de una

${ }^{3}$ Puede verse una descripción de este fondo de estabilización en Arellano (2005 y 2006) y en Velasco, Arenas, Rodríguez, Jorratt y Gamboni (2010).

${ }^{4}$ Véase la presentación del presidente del Banco Central, José De Gregorio, en los inicios de esta gran crisis (marzo 2008).

5 El impacto de las variaciones de precios en la industria del cobre es inevitable e incluso conveniente. Los productores ajustan su producción y hacen esfuerzos por adecuarse a la realidad de precios. Para los pequeños productores mineros se han ideado mecanismos de estabilización a través de Enami (Empresa Nacional de Minería) para hacer más gradual el ajuste a las nuevas condiciones. 
industria exportadora (por ejemplo, al afectar el desarrollo del transporte aéreo, marcas, protección fitosanitaria, la cantidad de recursos humanos especializados, etc.). La política fiscal contracíclica ha sido fundamental para lograr esta mayor estabilidad cambiaria, aun cuando la paridad resulta en promedio más apreciada en la bonanza de precios.

En este nuevo escenario, habiendo superado las inestabilidades y su alto costo, es posible concentrarse en cómo maximizar el impacto de la minería sobre el desarrollo.

\section{Nuestra participación en el mercado mundial}

En la actualidad, Chile produce el $35 \%$ de la producción mundial de cobre. Nunca antes durante el siglo XX tuvimos tan alta participación de mercado. En efecto, como puede verse en el Cuadro No 4 , hasta 1990 nuestra participación promedio en la producción mundial de cobre llegaba al $13 \%$, superando el $20 \%$ en los años 90 y alcanzando al $35 \%$ durante la primera década del siglo XXI. Esta participación no solo es muy alta sino que supera más de cuatro veces la participación de los siguientes mayores productores a nivel mundial: Indonesia y Estados Unidos.

En las reservas mundiales de cobre tenemos una participación del $30 \%$, lo cual nos permitiría mantener ese liderazgo mundial en las próximas décadas (véase el Cuadro $\mathrm{N}^{\circ} 5$ ).

En base a esas reservas actualmente existen proyectos de inversión para los años 2010-20 por más de U\$ 45.000 millones $^{6}$. Todo ello indica que nuestro liderazgo en la producción mundial debería mantenerse en los próximos 20 a 30 años 7 .

Esta situación nos da una oportunidad, que no habíamos tenido en el pasado, de desarrollar otras actividades alrededor del cobre y de atraer inversiones en actividades para-mineras, en negocios para atender la minería nacional y extranjera, aprovechando esa alta participación de mercado.

${ }^{6}$ Cochilco (Comisión Chilena del Cobre), "Inversión en la Minería Chilena del Cobre y del Oro Proyección del Período 2010-2015" (2010a). Actualizada a mayo 2010, estima que dentro del período 2010-2015 los proyectos que ya se encuentran en construcción y aquellos con probabilidades de iniciar su construcción suman U\$ 41.000 millones.

${ }^{7}$ Países tradicionalmente mineros están viendo disminuir sus reservas. Por ejemplo, Canadá ha disminuido sus reservas de cobre en más de $60 \% \mathrm{y}$ estima que le quedan menos de diez años (The Mining Association of Canada Mineral Production and Community Economic Development, 2005). 


\section{CUADRO N ${ }^{\circ}$ 4: $\quad$ PRODUCCIÓN MUNDIAL Y CHILENA DE COBRE DE MINA 1950-2009}

\begin{tabular}{lccc}
\hline Año & $\begin{array}{c}\text { Producción mundial } \\
\text { promedio } \\
\text { (miles de T.M.) }\end{array}$ & $\begin{array}{c}\text { Producción Chile } \\
\text { promedio } \\
\text { (miles de T.M.) }\end{array}$ & $\begin{array}{c}\text { Participación } \\
\text { de Chile } \\
\text { promedio (\%) }\end{array}$ \\
\hline $1950-1955$ & $2.786,2$ & 385,1 & \\
$1956-1960$ & $3.681,2$ & 502,1 & 13,8 \\
$1961-1965$ & $4.699,6$ & 587,9 & 13,7 \\
$1966-1970$ & $5.625,8$ & 664,5 & 12,5 \\
$1971-1975$ & $7.199,7$ & 778,2 & 11,9 \\
$1976-1980$ & $7.856,8$ & $1.044,8$ & 10,8 \\
$1981-1985$ & $8.191,9$ & $1.245,5$ & 13,3 \\
$1986-1990$ & $8.761,6$ & $1.493,6$ & 15,2 \\
$1991-1995$ & $9.557,6$ & $2.102,2$ & 17,0 \\
$1996-2000$ & $12.171,6$ & $3.837,6$ & 21,9 \\
$2001-2005$ & $14.185,5$ & $4.991,4$ & 31,4 \\
$2006-2009$ & $15.571,8$ & $5.408,8$ & 35,2 \\
\hline
\end{tabular}

Fuente: World Metal Statistics, producción mundial.

Codelco

Otros de Chile

Perú

México

Estados Unidos

Indonesia

China

Polonia

Rusia

Australia

Otros países

Fuente: U.S. Geological Survey, enero 2010. 
Además contamos con la ventaja de que el resto de los productores de cobre están geográficamente muy cerca. En efecto, América Latina concentra el $43 \%$ de la producción y el $48 \%$ de las reservas mundiales de cobre (Australia, uno de nuestros principales competidores, no tiene esa ventaja de localización). Pero es más conveniente hacer los análisis de competitividad por cadenas de valor. Pues bien, en el caso de los productos que tienen un origen minero, una parte de la cadena productiva tiene que localizarse donde están los yacimientos. Hay que procurar apalancarse en esa parte de la cadena para desarrollar otras partes de la cadena buscando oportunidades de valor y, de esa manera, ir moviéndose hacia arriba. El hecho de estar en la parte que genera rentas, si no se tiene una visión de largo plazo, puede restar incentivos para buscar el desarrollo de otras partes de la cadena.

Nuestro liderazgo en la producción mundial tiene como base la riqueza minera, pero ello no es suficiente. El liderazgo obedece a que Chile es uno de los lugares más atractivos y competitivos del mundo para hacer minería. El riesgo político es bajo gracias a la solidez de nuestras instituciones, existe la infraestructura de transporte interno y hacia los mercados, existe abastecimiento confiable - aunque carode energía, y están disponibles los servicios e insumos necesarios para desarrollar minería moderna de manera eficiente y competitiva.

Esta es una base muy importante que hay que preservar y desarrollar, cuidando nuestra institucionalidad, manteniendo la infraestructura y los insumos.

En cuanto a la infraestructura productiva, la disponibilidad de energía segura y a precios competitivos ha sido uno de los desafíos recientes. En materia de factores críticos, los recursos humanos especializados y la disponibilidad de agua ocupan un lugar prioritario. Sobre estos temas se vuelve más adelante.

Este liderazgo indiscutido en cobre no se repite en otros minerales. Aunque el país también tiene una participación importante en la producción y/o reservas de molibdeno, nitratos, plata, potasio, litio, su participación en la minería mundial no alcanza los niveles de liderazgo exhibidos en el cobre ${ }^{8}$.

\footnotetext{
${ }^{8}$ Puede verse Anderson (2009).
} 


\section{Las perspectivas del mercado}

El consenso respecto del mercado de cobre es que este seguirá siendo positivo para los productores en el próximo decenio. Vale decir, con la información actual, se prevé la continuación del escenario de altos precios que se han registrado en el último quinquenio, con una corta interrupción por la gran crisis financiera internacional.

Desde el punto de vista de la demanda, los países emergentes, encabezados por China, junto con estar creciendo a ritmos sin precedentes están atravesando por una etapa de su crecimiento que es la más intensiva en el uso de materias primas como el cobre. La urbanización y la industrialización de estas economías demandan metales como el cobre. Diferente es lo que ocurre en etapas posteriores de desarrollo en que el crecimiento es intensivo en servicios. Véase el Grafico $\mathrm{N}^{\mathrm{o}} 2$ donde se muestra el consumo per cápita de cobre de acuerdo al nivel de ingreso por habitante.

Por ello en la primera década de los años 2000 más del $60 \%$ del aumento del consumo mundial de cobre provino de China y se estima que en los próximos 25 años la demanda mundial de cobre se duplicará a causa de la demanda en los países emergentes 9 .

A lo anterior se agregan los nuevos usos del cobre, que compensan y superan la sustitución motivada por los mayores precios relativos. En general la mayor eficiencia energética, en automóviles por ejemplo, y las energías alternativas de carácter renovable son más intensivas en cobre. La propiedad antibacteriana del cobre, recientemente reconocida por la EPA, abre un amplio campo de nuevas aplicaciones.

En cambio por el lado de la oferta hay dificultades para responder a esta demanda. Las leyes promedio de los yacimientos en explotación no solo han disminuido en los últimos 30 años sino que lo seguirán haciendo en el próximo decenio. Los nuevos descubrimientos son más profundos y su mineralogía es más compleja. Los descubrimientos de los años 80 estaban en su mayoría expuestos, los de la década pasada están ocultos.

Una mayor proporción de la producción provendrá de países con más riesgo; a su vez, los altos precios han generado más interrupciones

${ }^{9}$ Por cierto, parte de la demanda de cobre en China es para exportaciones y por tanto está sustituyendo demanda que antes provenía de otros países cuya producción de manufacturas ha sido sustituida por exportaciones chinas. 


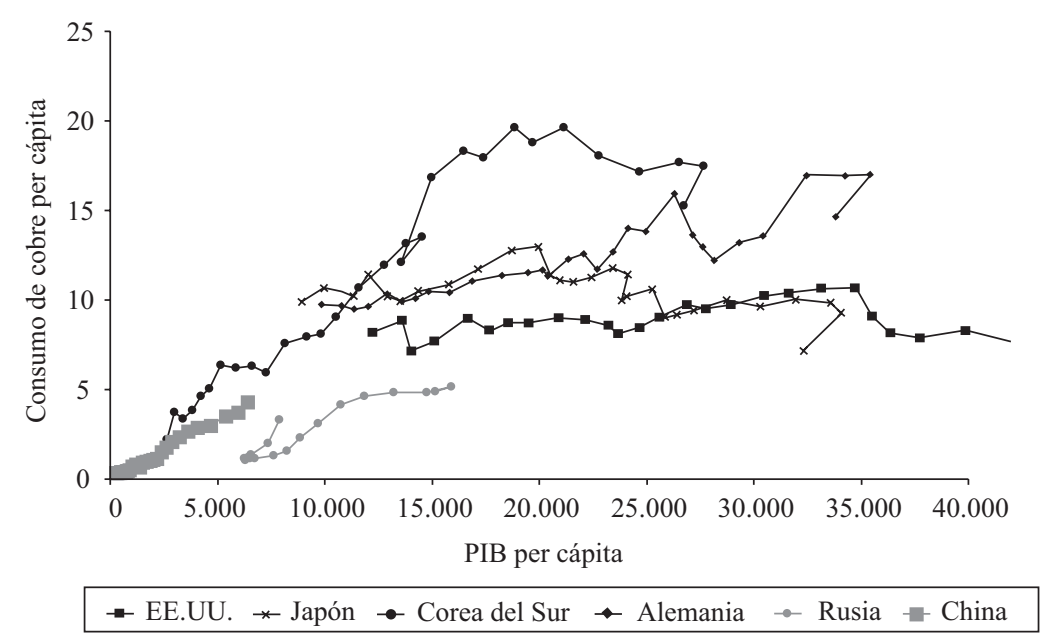

Fuente: FMI y Codelco.

en la actividad productiva y dificultades para cumplir con la producción programada.

Con todos estos elementos, las proyecciones de producción indican que las actuales operaciones, con las inversiones planeadas, en diez años más apenas superarán el nivel actual. La mayor parte del crecimiento tendrá que provenir de yacimientos nuevos en áreas de mayor riesgo y de proyectos que tendrán que desarrollarse contra el tiempo en escenarios difíciles.

Todo ello es lo que sustenta el consenso de un decenio de precios altos, aunque volátiles. Esto ofrece una oportunidad para los países productores como Chile para aprovechar esa bonanza y convertirla en un factor de desarrollo y generación de riqueza permanente.

\section{El impacto multiplicador en el desarrollo}

Más allá del importante impacto directo del cobre al desarrollo, este tiene el potencial de generar un efecto multiplicador al contribuir al desarrollo de actividades para-mineras que abastezcan a la minería nacional y extranjera. Aquello se ha denominado un cluster en torno a 
la minería ${ }^{10}$. Es lo que han hecho otros países que a partir de la riqueza minera y/o de otros recursos naturales han desarrollado industrias de bienes de capital, de insumos y de servicios.

Tradicionalmente, cuando se ha propuesto ampliar la contribución del cobre al desarrollo del país, se ha pensado en la integración vertical ${ }^{11}$. Vale decir, en llegar con producción más allá de concentrado de cobre, incluyendo su refinación y ojalá la producción de manufacturas de cobre. Estas son actividades industriales intensivas en capital y en energía, que requieren de gran escala para ser competitivas y cuya rentabilidad es estrecha. Sin perjuicio de que haya actividades que puedan ser rentables en esta etapa de la cadena productiva, lo que aquí se quiere destacar es que hay un ámbito mucho más amplio, con menores requerimientos de capital, con efectos multiplicadores mucho mayores y con una diversidad de oportunidades que son los servicios e insumos para la minería, o actividades para-mineras, con las cuales se puede formar un cluster productivo.

Es importante tener en cuenta ciertas características distintivas de la industria minera del cobre que hacen posible y necesario capturar sus impactos multiplicadores, desarrollando ciertas capacidades productivas en el país y/o desarrollando ventajas comparativas que puedan contribuir al crecimiento más allá y de manera más duradera que la producción directa de las minas.

El cobre es un recurso no renovable, de allí la importancia de aprovechar su desarrollo para generar otras fuentes de riqueza que sobrevivan al agotamiento del recurso minero. Esto hace aconsejable aprovechar la etapa de inversión y producción minera para el desarrollo de otras capacidades productivas conexas. Esa ha sido la experiencia de los países más exitosos en convertir los recursos mineros en fuente duradera de desarrollo. De hecho la regla de Hartwick (véase Recuadro No 1 ) estima cómo se debe aumentar la acumulación de capital para compensar el uso de recursos no renovables sin alterar el bienestar en el futuro.

${ }^{10}$ Seguimos la definición de cluster de M. E. Porter como un grupo de empresas interconectadas, universidades y otras entidades relacionadas, concentradas geográficamente que surgen como resultado de las externalidades resultantes en la industria. Joseph Ramos (1999), en "Una estrategia de desarrollo a partir de los complejos productivos (clusters) en torno a los recursos naturales, ¿una estrategia prometedora?", examina las ventajas de los clusters en torno a recursos naturales.

${ }^{11}$ Véase un completo recuento de este debate en Meller (2002), en particular el artículo del mismo autor "El cobre chileno y la política minera". 


\section{RECUADRO No 1}

\section{Explotación de recursos no renovables y crecimiento sustentable}

Por definición, la explotación de un recurso no renovable significa que se consume el recurso y que, por tanto, parte de sus retornos deben invertirse si se quiere mantener el nivel de consumo o bienestar en el tiempo. Esto, que está en el sentido común, no siempre se cumple y es una de las razones por las cuales los recursos mineros no contribuyen a un desarrollo sostenido de los países. Si no se hacen las inversiones para reemplazar el "capital de recursos naturales" que se ha consumido por otro capital físico o humano que sea reproducible, se agota el potencial de crecimiento a medida que se agotan las reservas de capital natural.

La regla de Hartwick (1977) ${ }^{1}$ establece que las rentas de la minería deben invertirse para asegurar un nivel de consumo sostenible en el tiempo.

Para que ello ocurra se requiere que las instituciones garanticen que tales rentas se ahorren y se canalicen a inversiones rentables. Nada de ello está garantizado. Así lo muestra la historia de los países ricos en recursos naturales no renovables.

Un interesante estudio del Banco Mundial, "Where is the Wealth of Nations? (2006)"2, realizó estimaciones de la riqueza en más de 140 países, incluyendo la riqueza en recursos naturales, mostrando tendencias en el tiempo así como las diferencias entre países de distintos niveles de ingreso por habitante. En los países de ingreso más bajo la riqueza en recursos naturales es la predominante. Con el aumento de ingresos los países van acumulando riqueza en capital producido y en activos intangibles (capital social, fortaleza institucional, entre otros). El proceso de desarrollo puede verse como uno en el cual los países exitosos van siendo capaces de transformar las rentas de la explotación de recursos naturales en otras formas de capital. Se van diversificando. Un requisito básico para este proceso es que se ahorren e inviertan esas rentas.

En la medida que en la mayoría de los países el Estado capta parte importante de las rentas de los recursos naturales, es determinante la existencia de mecanismos en la institucionalidad del Estado para asegurar que esos ingresos se ahorren e inviertan productivamente.

${ }^{1}$ John M. Hartwick (1977), un economista canadiense, desarrolló esta formulación motivado precisamente por el uso de los retornos de los recursos no renovables en su país.

${ }^{2} \mathrm{http}$ ://siteresources.worldbank.org/INTEEI/214578-1110886258964 /20748034/All.pdf. 
Asimismo, la explotación moderna de cobre es altamente intensiva en capital con altos costos hundidos y largos periodos de explotación y recuperación de las inversiones, lo cual limita el impacto directo en el empleo y el desarrollo. La actividad de servicios a la minería en cambio es menos intensiva en capital y varios de esos servicios, como los de ingeniería o los tecnológicos, son intensivos en conocimiento.

Los cambios tecnológicos hacen hoy día más factible desarrollar una industria proveedora de servicios que abastezca a la minería local y que exporte sus servicios a la minería mundial de lo que era en el pasado. El principal cambio tecnológico tiene que ver con los cambios en la organización de las empresas en las diferentes industrias y en la minería en particular que las ha llevado a concentrarse en su negocio principal y a subcontratar el resto de las actividades.

No era así en el pasado cuando las empresas mineras eran autosuficientes y se autoabastecían de la mayor parte de los insumos y servicios que requerían.

En el caso de Codelco, cuyas operaciones principales datan de principios del siglo XX, hace treinta años por cada cinco trabajadores de Codelco había uno que pertenecía a empresas contratistas. Actualmente por cada cinco trabajadores de Codelco hay siete trabajadores contratistas prestando servicios en las instalaciones de la empresa. Esa misma proporción muestran las empresas de la gran minería privada que se han formado en Chile a partir de los años 80. En el Grafico $\mathrm{N}^{\circ} 3$ puede verse cómo ha crecido la proporción que representan los servicios de terceros dentro de los costos de operación. Este cambio en la organización de las empresas mineras ha abierto espacio a numerosas empresas especializadas en la prestación de servicios, las cuales en la medida que se desarrollan y son competitivas pueden exportar sus servicios.

Esta realidad es muy distinta de la que se registraba en la época en que la minería constituía un verdadero enclave: empresas autosuficientes con sus trabajadores viviendo en campamentos; faenas conectadas con el exterior a través de insumos importados y exportación de los minerales con muy limitados efectos multiplicadores sobre la economía nacional. En la actualidad la conectividad física y las tecnologías de comunicación e información permiten una conectividad permanente entre la mina y cada una de sus instalaciones, equipos y personas y cualquier lugar que se desee. 


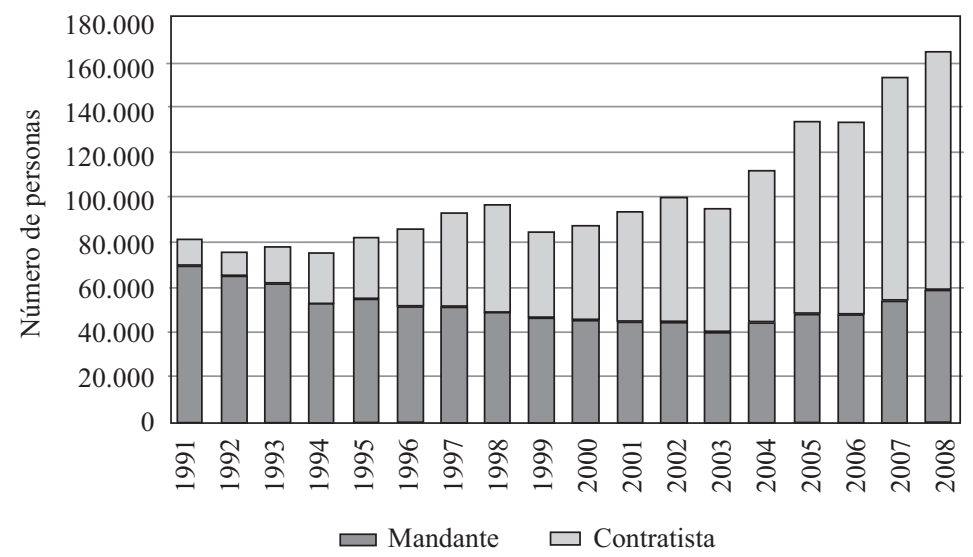

Fuente: Sernageomin (Servicio Nacional de Geología y Minería).

Aparte de los cambios en la organización de las empresas, la demanda de conocimiento y tecnología ha sido y seguirá siendo cada vez mayor. Los minerales que se explotan son de menores leyes, con una mineralogía más compleja; están más profundos y requerirán de explotación subterránea, crecientemente operados en forma remota. Asimismo, los requerimientos en materia de sustentabilidad ambiental necesitan tecnologías más eficientes en el uso de los recursos básicos como el agua y la energía y de un mejor tratamiento de los residuos y emisiones. Todo ello plantea nuevos desafíos y requerimientos y abre enormes campos de desarrollo tecnológico y de prestación de servicios especializados.

Estos servicios han sido correctamente llamados servicios intensivos en conocimiento ${ }^{12}$ por su alta especialización, y la necesidad de continua innovación e incorporación de tecnologías para buscar soluciones nuevas y más eficientes a los problemas de los proyectos y la operación minera.

Estos desarrollos tecnológicos y servicios no son exclusivos de la minería y generalmente pueden ampliarse a los mercados que ofrecen otras industrias. En particular a toda la industria de recursos naturales con la cual existe una convergencia de tecnologías.

${ }^{12}$ Osvaldo Urzúa (2007). 
Las experiencias exitosas en el desarrollo de actividades paramineras no son pocas. Hay varios países que fueron ricos en recursos mineros y que a partir de la minería desarrollaron las industrias de su entorno. En Estados Unidos y Canadá se desarrolló la industria de equipos mineros, en Finlandia la metalurgia y los servicios tecnológicos, Australia tiene un activo programa para desarrollar la industria de software y tecnología para la minería.

Es interesante referirse a algunas de ellas como ilustración para luego identificar lo que se podría hacer en Chile para avanzar en esa línea.

Finlandia, en la actualidad, prácticamente no tiene minería, porque sus reservas se agotaron, y sin embargo ha ganado una posición de liderazgo en tecnologías para el sector. Las empresas finlandesas de tecnología para la minería, entre las que se pueden mencionar Metso y Outotec, tienen su origen a principios del siglo XX con la apertura de nuevas minas. Ello llevó al desarrollo de la metalurgia. Esas empresas se han convertido en compañías que exportan servicios y tecnología para la minería prácticamente en todo el mundo. Metso tiene hoy más de 27.000 profesionales en el mundo, incluye no solo minería sino también soluciones para las áreas de productos forestales y energía. Outotec emplea más de 3.000 profesionales. Ambas compañías han crecido con su propio desarrollo tecnológico al cual han agregado en los últimos años la adquisición de otras empresas que complementan sus áreas de especialización. De esa forma pueden entregar una amplia gama de servicios tecnológicos a las empresas mineras.

Finlandia apoya el desarrollo de estas empresas con una política de colaboración estrecha entre las empresas productivas, el sector público y las universidades.

Australia está desarrollando junto a la actividad minera una industria de servicios tecnológicos para la minería. Más del $60 \%$ del software utilizado por la minería mundial es provisto por compañías australianas. Las exportaciones del sector de servicios y tecnología para la minería superan los tres billones de dólares. Esta actividad es menos intensiva en capital que la minería y genera empleos de calidad. Un estudio de la industria de servicios tecnológicos para la minería en Australia ${ }^{13}$ reporta que alrededor de 2001 esta se hallaba integrada por

${ }^{13}$ OECD (2005). 
más de 500 empresas con ventas por más de U\$ 2 billones con tasas de crecimiento de dos dígitos, empleando más de 17.000 personas, en su gran mayoría de alta especialización.

En Canadá más de 3.100 empresas prestaron servicios a la minería en el 2009, entre las cuales hay 238 compañías que prestan asesoría en temas medioambientales, 152 en temas financieros y de administración y 140 en exploración ${ }^{14}$.

En Chile se ha venido desarrollando la industria de servicios para la minería. Si se mira históricamente, los primeros pasos fueron para sustituir las importaciones de insumos y servicios ${ }^{15}$. En la segunda mitad del siglo XX la proporción de insumos nacionales se elevó desde menos del $25 \%$ en los años 50 a cerca del $60 \%$ a fines del siglo ${ }^{16}$. En los últimos seis años las exportaciones de proveedores para la minería crecieron desde 50 a 200 millones de dólares. Las exportaciones de servicios de ingeniería que bordeaban los diez millones de dólares a principios de los años 2000 superaron los 200 millones de dólares en el $2011^{17}$. El crecimiento es todavía mayor si consideramos que se han sustituido importaciones de estos servicios por oferta en el país. La ingeniería de los grandes proyectos mineros construidos en los 80 y los 90 se hizo fuera del país mientras que en los últimos quince años se hace mayoritariamente en Chile. La actividad de las empresas de ingeniería, medida como horas-persona, aumentó un 20\% entre 1992 y 2003 y, entre este último año y el 2011, creció en un 115\%. El principal crecimiento, lejos, se ha registrado en la ingeniería contratada por la minería, la que representó más del $50 \%$ del total el $2011^{18}$.

Pero si miramos a Australia, Estados Unidos o Canadá, en comparación al tamaño relativo de nuestro sector minero las exportaciones chilenas debieran superar largamente el nivel actual (véase el Cuadro $\mathrm{N}^{\mathrm{o}} 6$ ).

14 Datos de Global Infomine citados por ADCAM Media Group, "Mining Sector 2010: An Underground Payload" en Leadership Vision Series.

${ }^{15}$ Desde los años 50 hasta mediados de los 70 en que la economía se abre a las importaciones, las políticas de comercio internacional buscaron promover esa sustitución con variados resultados. Véase el recuento de Ffrench Davis (1974) en el capítulo "Integración de la Gran Minería a la Economía Nacional: El Rol de las Políticas Públicas”.

${ }^{16}$ Véanse Ramos Joseph (1998); Lagos y Blanco (2010).

${ }^{17}$ Asociación de Empresas Consultoras de Ingeniería (AIC) en base a datos del Servicio de Aduanas.

${ }^{18}$ AIC, Índice de actividad AIC sector ingeniería de consulta 2011, contruido en base a una muestra de empresas de esa asociación. 


\begin{tabular}{|c|c|c|c|c|}
\hline \multirow[b]{2}{*}{ País } & \multicolumn{4}{|c|}{ Exportaciones de la minería metálica y no metálica* } \\
\hline & 2006 & 2007 & 2008 & \\
\hline Chile & 38.229 & 44.226 & 42.862 & \\
\hline Canadá & 60.753 & 72.561 & 80.099 & \\
\hline \multirow[t]{2}{*}{ EE.UU.** } & 66.800 & 69.600 & 71.200 & \\
\hline & \multicolumn{4}{|c|}{ Exportaciones de proveedores mineros } \\
\hline País & 2006 & 2007 & 2008 & 2009 \\
\hline Chile & 183 & 149 & 234 & 173 \\
\hline Canadá & 3.983 & 4.032 & 4.081 & 2.681 \\
\hline EE.UU. & 13.288 & 15.814 & 18.128 & 12.701 \\
\hline
\end{tabular}

*: No incluye minerales combustibles (petróleo, carbón y gas).

**: Las cifras corresponden al valor de la producción de la minería metálica y no metálica.

Fuente: Exportaciones y producción minera: Cochilco, NRCAN (Natural Resources Canada) y USGS (U.S. Geological Survey). Exportaciones de proveedores mineros: Servicio Nacional de Aduanas, Industry Canada y United States International Trade Commission.

Hay un enorme espacio de crecimiento para las exportaciones de productos y servicios que abastecen a la minería. Si Chile alcanzara el nivel de exportaciones para-mineras como proporción de las exportaciones mineras que ha logrado Canadá, eso le significaría un crecimiento de más de diez veces el nivel actual.

Corresponde preguntarse entonces, ¿cómo acelerar y ampliar el efecto multiplicador de la minería en el desarrollo nacional? ¿Cómo promover el desarrollo de las empresas dedicadas a actividades paramineras? ¿Qué iniciativas de políticas públicas pueden apoyar una actividad que necesariamente deben hacer las empresas privadas? ¿Cuál es el rol de la política pública en este ámbito?

El Estado debe contribuir proporcionando los bienes públicos o semipúblicos que facilitan el desarrollo de estas actividades. En primer lugar puede promover que los distintos stakeholders discutan y construyan una "Visión del sector". La visión es un ejercicio prospectivo a quince o veinte años en el cual se revisan desafíos y oportunidades del sector. Los productores mineros aportan con sus perspectivas de inversión y las necesidades de servicios así como los principales desafíos 
tecnológicos; las autoridades con la identificación de los problemas regulatorios; los productores de insumos con sus capacidades y conocimiento de otros proveedores externos; las universidades con las proyecciones de formación de recursos humanos y capacidades tecnológicas, entre otros. Más importante que el carácter predictivo de esta Visión es el proceso de construcción y elaboración. Por ello se requiere de la participación activa de los stakeholders relevantes en este proceso para ir generando el diálogo, las redes e iniciativas de colaboración y coordinación resultantes de una visión compartida. Por la misma razón este es un ejercicio que conviene repetir cada cierto número de años. La elaboración de una visión del sector es una práctica común en los países que han sido más exitosos en el desarrollo de una industria para-minera ${ }^{19}$.

Otro bien público al cual el Estado puede contribuir son los estándares.

Hay numerosos detalles en sus procedimientos de abastecimiento, por ejemplo, en que los productores pueden ponerse de acuerdo para hacer más eficiente el proceso y dar facilidades a los proveedores, contribuyendo así a su desarrollo. Hay información que se puede compartir y actualizar respecto a los calendarios de inversión y a sus necesidades, que será muy valiosa para los proveedores.

En materia de TICA (tecnologías de información, comunicaciones y automatización), de creciente importancia para la minería, son necesarios estándares compartidos por la industria minera y los proveedores tecnológicos, que Chile puede liderar en su determinación, en conjunto con otros mercados de la región ${ }^{20}$.

19 Pueden verse algunos ejemplos de documentos donde se recoge la visión del sector. En Suecia, el informe Mining for Development a Preparatory Study (preparado por Global Utramining and Raw Materials Group, 2009) presenta la estrategia sueca y propuesta de iniciativa de carácter internacional. En Australia, véase "Australia 2030, Vision 2020 Project: The Australian Minerals Industry's Infrastructure Path to Prosperity" (2009), preparado para Minerals Council of Australia, y "Vision 2040, Mining, Minerals and Innovation" (http://resourcefutures.net.au/sites/default/files/draft_consultation pre_survey_030511.pdf), preparado por Mason, Lederwasch, Daly et al. (2011).

20 Codelco tiene un liderazgo importante en el país en tecnologías de información, comunicaciones y automatización gracias a su equipo profesional, a sus empresas tecnológicas y a una política sostenida en esta línea por más de diez años. Pueden verse algunos antecedentes del Codelco Digital en http:// www.codelco.com/hacia_futuro/tic.asp. En materia de estándares Codelco está llevando adelante en conjunto con Freeport y la Universidad de Chile un proyecto para su elaboración (SOMI - Standard Object for Mining Industries). 
Por medio de la asociatividad y la cooperación se construyen estándares comunes, se superan dificultades regulatorias para la exportación, y se obtienen facilidades para el transporte y la apertura de nuevos mercados, entre otros. Estos son esfuerzos muy costosos y lentos si los realizan empresas que están en su etapa de desarrollo, pero que si abordan en forma colaborativa, pueden ahorrarse costos y elevarse la rentabilidad.

El Estado puede jugar un lugar determinante ayudando a la industria en la fijación de estos estándares. Este es otro bien público para la industria.

En materia de tecnología y conocimiento el Estado y sus programas de apoyo al desarrollo tecnológico, junto a las universidades, requieren de esta asociatividad para alinearse con las necesidades del sector. Una Visión compartida del sector es importante para ayudar a orientar los esfuerzos de investigación.

Véase por ejemplo el trabajo que realiza en Australia el CSIRO (Commonwealth Scientific and Industrial Research Organisation), su agencia nacional para el desarrollo científico y tecnológico, que tiene entre sus áreas prioritarias el desarrollo de la minería y sus servicios, con un trabajo continuo durante las últimas décadas ${ }^{21}$. En Chile se han venido haciendo esfuerzos y aportando crecientes recursos, aunque aún insuficientes en comparación con otros países. Desafortunadamente, a su vez, esos esfuerzos son muy fragmentados, lo cual los hace menos relevantes y efectivos. Varias universidades están realizando esfuerzos paralelos y no cooperativos. Nuestras capacidades científicas y tecnológicas son reducidas en comparación con los países más exitosos y avanzados. En vez de reconocer esa realidad y sumar esfuerzos, se produce una excesiva competencia y fragmentación entre las universidades, sin alcanzarse la escala y continuidad en el tiempo necesarias para lograr resultados relevantes. Esto que es cierto para las actividades de investigación se da en la misma forma en la formación de los recursos humanos. Más adelante se analiza el tema de los recursos humanos y tecnología.

Entre las iniciativas privadas conviene destacar el interesante programa que están llevando adelante BHP Billiton y Codelco para con-

21 El CSIRO (Commonwealth Sicentific and Industrial Organization) elabora un documento de visión del sector que define sus prioridades, titulado "Minerals Down Under National Research Flagship". 
tribuir al desarrollo de proveedores de clase mundial. El programa tiene como meta llegar en 2020 a un total de 250 empresas proveedoras en esta categoría. En 2010 el programa se propuso trabajar con 50 empresas, número que debería duplicarse el año $2011^{22}$. Esta es una valiosa experiencia en marcha, a la cual adherirán otras grandes mineras, que puede facilitar el crecimiento de proveedores sin necesidad de otorgar concesiones especiales.

En síntesis, como nunca antes en la historia de nuestra minería hay un potencial multiplicador de su impacto sobre el desarrollo nacional. Ello puede ser mejor aprovechado en términos de velocidad y magnitud del impacto si se promueve la cooperación y asociatividad.

\section{Recursos humanos}

En cualquier actividad productiva la calidad y cantidad de recursos humanos disponibles resultan esenciales. Ello se vuelve más importante en la medida que el conocimiento cobra mayor relevancia para esa actividad. Es el caso, como hemos señalado, de la minería y de la industria para-minera.

Precisamente las diferencias en la preparación de los recursos humanos es la que explica el éxito de los países que han tenido más éxito en multiplicar el impacto de la minería en su desarrollo.

La comparación entre Chile y Estados Unidos es interesante a este respecto. Se estima que en la segunda mitad del siglo XIX ambos países tenían tecnologías similares en la explotación de cobre, sin embargo a principios del siglo XX se había producido una brecha importante que llevó a que las nuevas explotaciones de gran minería en Chuquicamata y en El Teniente fueran realizadas por capitales y tecnologías norteamericanas. Estados Unidos reemplazó a Chile como principal productor mundial de cobre durante la mayor parte del siglo XX.

En los Estados Unidos hubo un fuerte impulso a la educación secundaria a fines del siglo XIX y principios del siglo XX, logrando el liderazgo mundial en educación secundaria y superior. Aparte de masiva, de jornada completa, con una formación académica con base científica

${ }^{22}$ Es una iniciativa que inició BHP y a la cual se sumó Codelco en enero del 2010. Véase la presentación de Osvaldo Urzúa (2007), líder del programa Proveedores de Clase Mundial para la Industria Minera Global. 
y práctica, la educación secundaria y superior en Estados Unidos logró ventajas importantes sobre los modelos europeos de la época ${ }^{23}$.

Entre los avances educacionales destaca la formación de ingenieros de minas. Un censo realizado en 1916 en ese país determinó que había 7.500 ingenieros de minas, con experiencia en el país y en el extranjero $^{24}$. En Chile, en cambio, a esa fecha había menos de cien ingenieros de minas a pesar de que las diferencias de producción no justificaban esa brecha; por el contrario, hasta la década de 1880 Chile superaba en producción a los Estados Unidos. Entre 1916 y 1930 egresaron apenas 75 ingenieros de minas en nuestro país. De hecho, entre 1838, cuando se inicia la formación de ingenieros en Chile, y 1934, el total de ingenieros que se titulaban al año apenas alcanzaba a 14, el máximo se logró en la década de 1910 cuando se titularon 29 por año ${ }^{25}$. Esa cifra incluye civiles y mineros que en la época tenían mayor importancia relativa.

$\mathrm{La}$ insuficiente cantidad de jóvenes en carreras tecnológicas, y en particular en carreras vinculadas a la minería, metalurgia y geología, persiste hasta hoy día.

A partir de la década de 1980 hubo una marcada disminución en el número de estudiantes en carreras de minería. Ello a pesar del fuerte aumento de estudiantes de educación superior en el país. En el año 2006, en todo el país, se titularon 49 geólogos, 74 ingenieros civiles en minas y 76 ingenieros civiles en metalurgia, lo que es claramente insuficiente para las necesidades en Chile y peor aun si se considera que varios de estos profesionales están emigrando por las oportunidades que hay en otros países, ya que la escasez de este tipo de profesionales constituye una realidad a nivel mundial ${ }^{26}$.

${ }^{23}$ Véase por ejemplo el trabajo de Claudia Goldin, "The Human Capital Century and American Leadership: virtues of the Past", Economic History Association Presidential Adress 2000. NBER working Paper 8239.

24 Véase el interesante trabajo de Gavin Wright y Jesse Czelusta, Exorcizing the Resource Curse: Minerals as a Knowledge Industry, Past and Present (2002).

25 Vease un recuento histórico de la ingeniería chilena hasta 1935 en Santiago Marín Vicuña (1935).

26 Véase, por ejemplo, el informe sobre la realidad australiana en "Staffing the Supercycle: Labour Force Outlook in the Minerals Sector, 2005 to 2015" (2006), encomendado por el Minerals Industry National Skills Shortages Strategy (NSSS), financiado por el Department of Education, Science and Training de Australia. En el caso de Canadá pueden verse varios estudios y proyecciones realizados por el MiHR, ver http://www.mihr.ca/en/publications/ 
Entre 2000 y 2009, el número de estudiantes en la educación superior pasó de 358.082 a 615.405. Sin embargo, en las carreras mineras el número de estudiantes apenas aumentó en 634. La proporción de estudiantes en el ámbito de la minería bajó de $0,5 \%$ a $0,4 \%$ del total en el mismo periodo. Nótese que esta baja proporción es incluso menor que la de la minería en el empleo nacional.

En cuanto a los estudiantes de más alta preparación, que siguen estudios de postgrado, el país ha venido haciendo un esfuerzo creciente por apoyar una alta especialización en el extranjero de un grupo selecto de egresados de nuestras universidades. En los últimos diez años se han otorgado 9.600 becas de postgrados (en sus distintas modalidades: Presidente de la República, Becas Chile, etc.). De ellas apenas 61 se han destinado a estudios en especialidades mineras ( $0,6 \%$ del total). De los 1.917 estudiantes que han salido al exterior a estudiar con la Beca Presidente de la República, desde su creación en los años 80 , apenas trece lo ha hecho en las disciplinas de minería.

Todo ello revela la falta de prioridad y de importancia que recibe la formación de recursos humanos para la minería. Esto sucede a pesar que a los atractivos tradicionales de las actividades profesionales en el área minera se suman actualmente la mejor conectividad y la mayor seguridad y calidad de vida que ello conlleva. Asimismo, esta es una actividad cada vez más intensiva en el conocimiento y su gestión.

Un estudio reciente de las necesidades de recursos humanos para el periodo 2011-20 realizado por Fundación Chile (2011), por encargo de las grandes empresas mineras, concluye que "las brechas (o déficits proyectados) de fuerza laboral calificada constituyen, probablemente, el mayor desafío que enfrenta el desarrollo de la gran minería chilena para la década 2011-2020". Se estima que el conjunto de las empresas mineras y contratistas de la gran minería requerirá hacer crecer su dotación en un 53\% entre 2012 y 2020, considerando solo sus operaciones de extracción, procesamiento y mantenimiento, situación que se torna particularmente crítica en algunos niveles y cargos específicos. Si se agregan las jubilaciones habría que sumar un $20 \%$ adicional de contra-

MiHRPublications.asp. Entre ellos, "Ontario Labour Market Demand Projections, Mining Industry Workforce Information Network", presentado en la Ontario Mining Association por la Mining Industry Human Resources (MiHR) Council, agosto 2009. 
taciones. Si se examina la oferta proyectada de egresados hay déficits claros para ciertas especialidades.

En este estudio, que es necesario actualizar periódicamente, se realizan también una serie de valiosas recomendaciones estratégicas para las instituciones formadoras de técnicos y profesionales para el sector.

Para multiplicar el impacto sobre el desarrollo de la explotación de sus recursos mineros el país necesita llevar al nivel de máxima excelencia a uno o dos consorcios de universidades chilenas, en las cuales se especialicen los mejores alumnos del país y del extranjero. Esos programas pueden ser en asociación con algunos de los mejores centros mundiales en la materia. Al mismo tiempo hay que formar y especializar un número bastante mayor de estudiantes en las disciplinas mineras y afines. Ellos darán la base al desarrollo productivo y tecnológico del sector y de la industria para-minera.

Lamentablemente observamos una excesiva multiplicación de programas y fragmentación de esfuerzos. Los programas de master y doctorado en carreras afines a la minería aumentaron de 14 en 2002 a 27 en 2006. Cada institución quiere tener su propio programa de postgrado. Más valdría tener uno o dos de clase mundial al que asistieran los alumnos chilenos y de otras partes del mundo.

La tendencia en otros lugares es precisamente la colaboración y asociación, un ejemplo es el programa de seis escuelas universitarias de minería en Europa (Federation of European Mining Programs, FEMP), que ofrece un master conjunto de esas escuelas de cuatro países europeos, European Mining, Minerals and Environmental Program $(\text { EMMEP })^{27}$.

Con un tercio de la producción mundial de cobre no hay razones para que en Chile no estén situados uno o dos de los principales centros de formación de recursos humanos del mundo. Ello requeriría sumar capacidades a nivel nacional y atraer talentos del resto del mundo. La excesiva competencia entre los centros de estudios, en otros aspectos positiva, vuelve lejana esta posibilidad a menos que se ejerza una acción decidida para promoverla.

27 Participan las siguientes instituciones: RWTH Aachen, Alemania; Delft University of Technology, Países Bajos; Camborne School of Mines, Reino Unido; Helsinki University of Technology, Finlandia; University of Miskolc, Hungría; Wroclaw University of Technology, Polonia. www.femp.org/ y /www.emmep.org/. El programa partió en 1996 y ha ido creciendo. 
Se requiere aquí, como en otros ámbitos, una mucho más estrecha colaboración entre el sector educacional y la industria minera y para-minera. Véase por ejemplo la experiencia en Canadá del Consejo MiHR, una asociación a la cual concurren las empresas, las instituciones de educación, los sindicatos y el gobierno. En ella se realizan estudios y se promueven iniciativas para el desarrollo de los recursos humanos del sector minero.

Asimismo nuestro sistema educacional debe poner mayor atención a la atracción de jóvenes hacia la formación en ciencias y tecnología. Una fracción demasiado baja de la enorme expansión en educación superior de los últimos diez años ha sido en ciencia y tecnología.

\section{Investigación y desarrollo}

En definitiva, el desarrollo del sector en el largo plazo estará determinado por el desarrollo tecnológico y la innovación. Esto es cierto para la actividad minera como para todos los servicios destinados a ella.

Los procesos mineros, al contrario de lo que a veces se pueda pensar, no están determinados por la calidad de los recursos que ofrece la naturaleza, pues la tecnología y la innovación juegan un papel muy determinante.

La opinión general es que la actividad minera es de baja innovación y poco intensiva en investigación y tecnología. Una de las razones para ello es que en minería la innovación principal no está en los productos. El cobre exportado actualmente es aparentemente muy similar al que se ha exportado por varias décadas, a diferencia de lo que ocurre en otras industrias donde la innovación en materia de productos es permanente. Piénsese en la electrónica e informática o en la industria farmacéutica, que están innovando continuamente en sus productos. En la minería del cobre, en cambio, se innova en los procesos productivos, los que están más lejos del público general y por tanto son menos visibles aunque son igualmente demandantes de los cambios tecnológicos y la innovación permanente.

Sin los cambios tecnológicos no sería posible explicar el fuerte aumento de la producción de cobre mundial registrado durante el siglo $\mathrm{XX}$, de más de veinte veces, al mismo tiempo que la ley media del mineral bajó de cerca de $2 \%$ a $0,7 \%$, logrando, además, que el costo de producción por libra bajara en términos reales. 
Otro ejemplo en el mismo sentido lo ofrece la significativa transformación que se registró en la minería del cobre en los Estados Unidos a partir de la crisis de los años 80. Ella fue resultado de importantes mejoras tecnológicas que permitieron triplicar la productividad por trabajador entre fines de los 70 y principios de los 90 y así revitalizar la industria del cobre y evitar su cierre ${ }^{28}$.

Dado que la innovación se da en los procesos, parte importante de los cambios tecnológicos son realizados por los fabricantes de plantas y equipos, la mayor parte de los cuales son importados a Chile.

La demanda actual de cambios tecnológicos para la minería proviene desde distintos ámbitos. Por una parte de la introducción de las nuevas tecnologías transversales de carácter disruptivo, en particular las tecnologías de información y comunicaciones. La minería está en el proceso de incorporar todas las oportunidades que le ofrecen estas nuevas tecnologías. En particular la operación remota de minas, la automatización y la robótica. Ello va a facilitar la producción en operaciones subterráneas y de alta cordillera y en general en ambientes muy adversos para el trabajador. Por otra parte, hay demandas que están asociadas a la exploración y a la capacidad de ver en profundidades, a la minería subterránea en general que será la predominante en las próximas décadas.

Otra fuente clave de demanda por innovación proviene de la sustentabilidad en sus variados ámbitos. Entre ellos, la necesidad de mayor eficiencia en el uso del agua y la energía en procesos que son intensivos en el uso de ambos recursos, asimismo en la reducción y recuperación de residuos, emisiones y la huella de carbono.

Más allá de la demanda general de innovación que enfrenta la minería mundial proveniente de la sustentabilidad, hay aspectos específicos propios de la realidad de la minería del cobre chilena referidos al agua, a la energía y a la huella de carbono. Los tres están interconectados. La energía se encareció de manera muy significativa con la disminución del abastecimiento de gas desde Argentina y el mayor costo del diésel y el carbón. En Codelco el costo por KWh se elevó desde cuatro centavos de dólar promedio entre 2000 y 2005 a once en 2009. Adicionalmente se elevó el consumo de energía (combustibles y

28 Véase el interesante análisis de este proceso realizado por John E. Tilton y Hans H. Landsber (1997). 
electricidad) por tonelada producida durante la década del 2000, a diferencia de lo que ocurrió en los 90. Durante los años 2000 el consumo de energía aumentó en 54\% mientras la producción lo hizo en 13,7\%. Esto es el resultado de leyes de mineral más bajas, mayores distancias de acarreo, mayor dureza del mineral y una cartera de productos más intensiva en productos refinados. A lo anterior se suma el que la matriz energética se ha vuelto más intensiva en diésel y carbón y por tanto en gases con efecto invernadero, todo lo cual ha llevado a un aumento en las emisiones en prácticamente todos los procesos productivos ${ }^{29}$. Las proyecciones para esta década indican que esta tendencia seguirá acentuándose. Cochilco ha estimado que la demanda de energía eléctrica se elevará en $52 \%$ entre 2008 y 2020 y que la matriz energética seguirá intensificando el uso de carbón ${ }^{30}$.

En cuanto al agua, en las regiones donde se realiza la mayor parte de la actividad minera, en el norte del país, la escasez y competencia por el recurso hídrico se han vuelto cada vez más intensas y esta situación se agudizará en el futuro ${ }^{31}$. Por tanto el uso de agua salada o el transporte de agua desde otros lugares se convierte en una alternativa. Estas alternativas de acceso al agua se traducen en mayor consumo de energía, de ahí que los tres temas estén estrechamente conectados.

Por consiguiente, el desarrollo de la minería chilena y su competitividad pasan por mejoras en la eficiencia en el uso y aprovechamiento de estos recursos. Junto con un desafío para el desarrollo del sector, se convierten en una oportunidad para la innovación.

La biotecnología, como otra tecnología transversal de carácter disruptivo, está siendo utilizada para avanzar en los procesos de biolixiviación, hasta llegar al ideal de la minería in situ.

En el año 2000 el Instituto de Política Científica y Tecnológica de la RAND convocó a ejecutivos de 58 empresas mineras en los Estados Unidos, proveedores de equipos e instituciones de investigación, para

${ }^{29}$ Cochilco (2010b).

${ }^{30}$ Cochilco (2010c). Esta mayor demanda de energía en las operaciones mineras también se da en otros países a consecuencia de la mayor complejidad de los minerales. En Australia, por ejemplo, la intensidad de uso de energía se elevó en $50 \%$ en la década del 2000 . Véase "Peak minerals in Australia:a Review of Changing Impacts and Benefits".

31 Durante la última década se produjo un importante mejoramiento en la eficiencia en el uso del agua. Pueden verse las estimaciones en Cochilco (2010d). 
examinar las tendencias de investigación y desarrollo tecnológico que se anticipaban para los siguientes 20 años en la minería de ese país. Las principales tendencias que se anticipaban dicen relación con desarrollos producto de la incorporación extensiva y creciente de las nuevas tecnologías de información y comunicaciones, la automatización y operación remota, el mantenimiento y la continuidad operacional y el mejoramiento de los grandes equipos mineros ${ }^{32}$. En 2003, la asociación de productores del cobre AMIRA, formada por iniciativa australiana, elaboró un mapa de necesidades tecnológicas a partir de las recomendaciones de un grupo de 40 especialistas de las empresas, universidades, proveedores de equipos y principales clientes. Allí se plantearon una serie de iniciativas de desarrollo tecnológico dirigidas a lograr como principales objetivos para el año 2020: elevar la eficiencia energética en $10 \%$, reducir costos, mejorar la seguridad y reducir el impacto ambiental de los procesos ${ }^{33}$.

Por todo lo dicho el liderazgo del país en la minería del cobre no permite descuidar el campo de la innovación y el desarrollo tecnológico.

Lamentablemente la innovación es un campo en el cual, a diferencia de otros, como la estabilidad macroeconómica o la integración a la economía mundial, el país está relativamente atrasado. Así lo han constatado diversos estudios de nuestra realidad. El informe de la OECD $(2007)^{34}$, por ejemplo, señala expresamente que en cuanto al desarrollo del sistema de innovación en Chile "se ha avanzado a un paso más lento de lo que se ha visto en el caso de otros pilares institucionales característicos de una economía de mercado eficiente". Las recomendaciones de ese informe así como las del informe encargado por la Comisión Nacional de Innovación al Banco Mundial (2008) ${ }^{35}$ respecto del sistema nacional de innovación, son válidas respecto de la innovación en la minería y son coincidentes con los puntos que se plantean a continuación.

¿Qué hacer, por tanto, desde el punto de las políticas públicas en este ámbito? Para ser efectivos en la promoción del desarrollo de capacidades y de una política que promueva la innovación, investigación y desarrollo en el sector, los países requieren de un esfuerzo sostenido a largo plazo. Los países más exitosos han hecho esfuerzos colaborativos entre

\footnotetext{
32 Peterson, LaTourrette y Bartis (2001).

${ }^{33}$ AMIRA (2004).

${ }^{34}$ OECD (2007).

${ }^{35}$ World Bank (2008).
} 
empresas, gobierno y universidades. Una de las deficiencias del sistema de investigación y desarrollo en Chile es que invierte una cantidad insuficiente de recursos, pero incluso más que ello es que el grueso de los recursos proviene del sector público y se canalizan a las universidades. Ello genera un riesgo alto de desconexión entre el esfuerzo de investigación y las necesidades del sector productivo. Por ello es indispensable promover el trabajo colaborativo entre empresas y universidades. La complejidad de los problemas tecnológicos exige una interacción permanente entre universidades y empresas en las distintas etapas del proceso. Asimismo, la creciente velocidad de los cambios hace indispensable esta colaboración. La encuesta a proveedores de la minería realizada en el 2006 en la Universidad Católica-Dictuc y Centro de Minería (2007), por encargo de Corfo, reportó que solo un $22 \%$ de las empresas proveedoras considera importante su interacción con entes universitarios y de investigación y que el 53\% no le atribuye ninguna importancia a esa relación para la innovación. En cambio el 73\% considera muy importante para la innovación la interacción con las empresas mineras.

Para favorecer los esfuerzos colaborativos, la Visión del sector a que se hizo referencia, para desarrollar las actividades para-mineras, es un marco necesario. La construcción de una visión compartida ha sido habitual en los países más exitosos de la OECD (véanse el informe y las recomendaciones de la OECD sobre innovación en Chile). Asimismo varios países han elaborado, a partir de la Visión, un "mapa" de necesidades y prioridades tecnológicas. En el caso de Australia, respecto a las empresas de servicios tecnológicos para la minería se construyó una Agenda de Acción (véase OECD, 2005) a principios de los años 2000, que ayudó a reducir la fragmentación. Estas empresas de servicios tecnológicos son parte importante del proceso de la innovación en la industria moderna y en particular en el caso de la minería.

En Estados Unidos, a fines de los 90 y principios de los 2000 se elaboró una serie de documentos con la Visión de la industria minera en 2020 y mapas del desarrollo tecnológico requerido ${ }^{36}$. Lo mismo ha hecho la industria minera canadiense (véase Canada Mining Innovation Council, 2008).

Como en toda actividad relacionada con la generación y difusión del conocimiento, la preparación y disponibilidad de recursos humanos

${ }^{36}$ Estos documentos se refieren a la industria minera en su conjunto, incluyendo al cobre. National Mining Association (1998a y 1998b). 
es crítica. Por tanto lo señalado en la sección anterior es válido en este caso. Los recursos humanos requeridos para investigación y desarrollo son los de más alto nivel de preparación y con especialización en las áreas de ingeniería y ciencias. El número de doctores en ciencias e ingeniería por millón de habitantes en Chile es la quinta parte del promedio en los países de la OECD. Asimismo, la cantidad de estudiantes chilenos por millón de habitantes que actualmente está en universidades en los Estados Unidos es muy inferior no solo a la de Corea, Taiwán o Singapur sino 40\% más baja que la de Australia (Banco Mundial, 2008). En los últimos años Chile ha estado haciendo un esfuerzo importante en esta línea, el cual, dado el atraso del cual se parte, debe mantenerse y en lo posible incrementarse en el tiempo.

Por último, como no es posible estar en todos los temas de manera exitosa es conveniente un análisis estratégico como parte de la Visión y/o del mapa tecnológico para hacer ciertas opciones estratégicas en términos de los campos en los cuales se quiere buscar un liderazgo ${ }^{37}$.

En la etapa de inversión de los proyectos mineros se adoptan una serie de decisiones tecnológicas de carácter muy estratégico y poco reversibles. En la medida que en los próximos años se invertirán cerca de 50 billones de dólares, esta es una etapa extremadamente fértil y relevante para la discusión del futuro tecnológico en la industria del cobre nacional. Tanto por las opciones que se eligen como por las oportunidades que se generan para la actividad para-minera en función de estas decisiones.

Ejemplos de iniciativas de colaboración en otros países son: AMIRA, creada hace más de 50 años por los diez líderes de la industria minera australiana de la época para realizar investigaciones de manera colaborativa, el Cooperative Research Centre for Landscape Evolution and Mineral Exploration (CRC LEME) establecido en Australia en 1995 con el apoyo de la industria, universidades y el CSIRO ${ }^{38}$.

${ }^{37}$ Puede verse una revisión de los enfoques en distintos países en Canadian Mining Innovation Council (2008a) "An Overview of Mining Research and Innovation Strategies in Selected Foreign Jurisdictions", realizado como parte del proceso para establecer una estrategia para Canadá ante la percepción de pérdida de liderazgo frente a Australia. Véase también Canadian Mining Innovation Council (2008b) "Pan-Canadian Mining Research and Innovation Strategy".

38 Véase un recuento de estos y otros ejemplos australianos en Robert LaNauze y Paul Greenhill (2009) y en Jim May (2006). 
La visión de innovación en Australia puede verse en "Venturous Australia Building Strength in Innovation: Review of the National Innovation System" $(2008)^{39}$, y un resumen de la forma en que se organiza el sector en World Bank (2008) $)^{40}$.

En síntesis, Visión compartida, mapa de desarrollo tecnológico, estrecha asociación entre universidades e industria, formación de recursos humanos de alto nivel son aspectos constitutivos para una política exitosa en materia de innovación y desarrollo tecnológico ${ }^{41}$.

\section{Consideraciones finales}

Durante la primera década de los años 2000 se llevaron adelante una serie de iniciativas dirigidas a desarrollar el llamado cluster minero. Entre ellas cabe destacar una serie de estudios de diagnóstico sobre la situación y potencialidades de ese cluster así como la forma de impulsarlo. Entre los principales estudios pueden destacarse los realizados por la Comisión Chilena del Cobre (Cochilco) (2001, 2005 y 2010), Meller y Lima (2003) por encargo del Consejo Minero, Boston Consulting Group (2007) por encargo del Consejo de innovación, Universidad Católica Dictuc-Centro de Minería (2007) e Innova (2009), encomendado por Corfo-Innova ${ }^{42}$. Ellos aportan antecedentes valiosos para el diagnóstico y proponen algunas iniciativas de acción.

Entre las políticas impulsadas en este periodo cabe destacar diversos apoyos con recursos desde Corfo y un esfuerzo de promoción desde el Ministerio de Minería ${ }^{43}$. En 2010 se interrumpió el impulso al cluster por las nuevas autoridades de Corfo para luego retomar el apoyo al programa de desarrollo de proveedores mineros y de apoyo a

${ }^{39} \mathrm{http}$ //www.innovation.gov.au/innovationreview/Pages/home.aspx.

${ }^{40}$ World Bank (2008).

${ }^{41}$ Son interesantes las reflexiones del profesor Steve Blank, invitado a conocer nuestro sistema de innovación, su sugerencia es que el ChileconValley debe desarrollarse apalancado de la industria minera.

${ }^{42}$ En las referencias al final de este artículo se encuentra el detalle de estos estudios.

${ }^{43}$ Se formó un Consejo Nacional Estratégico del Cluster Minero, véase la cuenta del Ministro de Mineria en enero del 2010. http://www.innovamineria.cl/archivos/Cuenta_Publica_Ministerio_Mineria.pdf. 


\section{RECUADRO No 2}

\section{Aprendizajes de los estudios sobre cluster}

Al menos desde Alfred Marshall (1920) se ha reconocido la importancia de la aglomeración de empresas geográficamente y las ventajas que se derivan de la formación de tales clusters de empresas. En las últimas décadas, Michael Porter (1990) ha desarrollado el concepto de cluster y su relevancia para entender la localización de empresas y la competitividad de ciertas regiones. Ello ha generado en el último tiempo una cantidad de estudios empíricos que aportan nuevos antecedentes. El Global Cluster Initiative Survey, mantiene un mapa con información de clusters en distintas partes del mundo, Ketels (2003) ofrece una muy buena síntesis conceptual del tema.

Desde el punto de vista que aquí nos interesa hay al menos tres cuestiones relevantes. La primera es que la existencia de un cluster tiene ventajas ya que genera un mayor crecimiento económico. La segunda se relaciona con los orígenes de esas ventajas y la tercera se refiere a cómo promover el desarrollo de un clúster, para lo cual hay que entender su dinámica y los factores que impulsan su desarrollo.

(i) La existencia de clusters genera mayor crecimiento económico en comparación a áreas donde estos no existen. Datos para 1990-2005 de diferentes clusters en los Estados Unidos muestran un mayor dinamismo económico, que se tradujo en mayor crecimiento del empleo, los salarios y formación de empresas en las regiones con mayor presencia de cluster (Delgado, Porter y Stern, 2010).

(ii) La cercanía geográfica de las empresas proporciona economías de transacción entre ellas y externalidades positivas. Estas están asociadas con: acceso a recursos humanos especializados y proveedores, difusión de conocimiento y aprendizaje de clientes y proveedores localizados en el área, aprovechamiento de complementariedades y un ambiente competitivo, facilitación de la innovación en la medida en que se puede lograr interacción con instituciones de investigación y desarrollo que se localizan en el área, y facilitación de la experimentación.

Las industrias extractivas tienen que localizarse donde están los recursos naturales. De lo que se trata es que estas atraigan la instalación de otras empresas de servicios que no solo tienen que localizarse obligadamente para prestar los servicios in situ, sino que desde ahí sirvan a otros mercados. La apreciación dominante es que este proceso de formación de cluster no es automático y/o puede acelerarse, generando el círculo virtuoso de las externalidades. Vale decir existen equilibrios múltiples. De lo que se trata es de moverse a un equilibrio superior. 
(iii) Condiciones básicas para facilitar la formación y crecimiento del cluster son el ambiente de negocios (instituciones y reglas propicias, estabilidad macroeconómica) y la infraestructura básica. Los principales objetivos de la política pública, cuando existen las condiciones anteriores, son remover los obstáculos para que se produzca la colaboración entre los participantes en el cluster, contribuir a la disponibilidad de bienes públicos o semi-públicos, y ser parte en la identificación de actividades colaborativas que elevan la productividad de las empresas participantes.

\section{Principales referencias sobre clusters}

Delgado, Mercedes, Michael E. Porter, Scott Stern (2010). "Clusters, Convergence, and Economic Performance". http://papers.ssrn.com/ sol3/papers.cfm?abstract_id=1695011.

Ketels Christian H. M. (2003). "The Development of the Cluster Concept: Present Experiences and Further Developments" http://www.isc.hbs. edu/pdf/Frontiers_of_Cluster_Research_2003.11.23.pdf.

Marshall, Alfred (1920). Principles of Economics. London: MacMillan, edición revisada.

Mac Millanand y M. E. Porter (1990). The Competitive Advantage of Nations. New York: Free Press.

la investigación con la instalación de un centro de excelencia para la minería ${ }^{44}$.

A pesar de la contribución de estos esfuerzos, lo cierto es que no existe una iniciativa de envergadura que promueva el desarrollo del cluster o de la industria para-minera. Aún no se ha construido una Visión compartida y no existen trabajos de coordinación y asociatividad permanentes entre los stakeholders. Existen iniciativas muy valiosas pero aisladas. No obstante, al mismo tiempo hay un dinamismo de la industria para-minera para aprovechar las extraordinarias condiciones de mercado, fruto de iniciativas empresariales y esfuerzos de emprendimiento muy destacables.

Sin embargo, no se está aprovechando todo el potencial. Resulta urgente aprovechar esta ventana única de oportunidad que se le está ofreciendo al país durante estos años y que no se repetirá a futuro. Este artículo ha pretendido crear conciencia entre los lectores sobre la urgencia de actuar para no desperdiciar esta oportunidad única.

${ }^{44}$ Ver las presentaciones del Subsecretario de Minería y el Vicepresidente del Corfo Abril 2011. http://www.corfo.cl/opensite_det_20110421122323.aspx. 


\section{REFERENCIAS}

Anderson, Steven T. (2009). "The Mineral Industry of Chile". En http:// minerals.usgs.gov/minerals/pubs/country/2009/myb3-2009-ci.pdf.

AMIRA (2004). “Copper Technology Roadmap". En http://www.energetics. com/resourcecenter/products/roadmaps/Documents/CopperTechnology-Roadmap.pdf.

Arellano (2005). "Del Déficit al Superávit Fiscal: Razones para una Transformación Estructural en Chile", 'Serie Estudios No 25, Cieplan.

"Del Déficit al Superávit Fiscal: Razones para una transformación estructural en Chile". Estudios Públicos, Nº 101 (2006).

Boston Consulting Group (2007). "Estudios de Competitividad en Clusters de la Economía Chilena" del Consejo Nacional de Innovación para la Competitividad. En http://www.bligoo.com/media/users/3/182374/ files/18813/Documento\%20de\%20Referencia\%20Mineria.pdf.

Canadian Mining Innovation Council (2008a). "An overview of mining research and innovation strategies in selected foreign jurisdictions". (2008b) "Pan-Canadian Mining Research and Innovation Strategy". (2008c) Innovation Research \& Development Needs Background Papers http://www.cmic-ccim.org/en/knowledgecentre/innovation research_development_needs_papers_2008.asp\#01

Cochilco (2005). Oportunidades de Negocios para Proveedores de Bienes, Insumos y Servicios Mineros en Chile. http://www.cochilco.cl/productos/ pdf/oportunidades_de_negocios_para_proveedores_en_chile.pdf.

- (2010a). "Inversión en la Minería Chilena del Cobre y del Oro, Proyección del Período 2010-2015".

- (2010b). "Consumo de Energía y Emisiones de Gases de Efecto Invernadero Asociadas de la Minería del Cobre de Chile. Año 2009”.

- (2010c). "Demanda de Energía Eléctrica en la Minería del Cobre y Perspectivas de Seguridad en su Abastecimiento".

(2010d). "Consumo de Agua en la Minería del Cobre 2009".

(2010e). "Análisis Demanda-Oferta de Ingeniería de Proyectos en la Industria Minera”. En http://www.cochilco.cl/productos/pdf/2011/ Analisis_Demanda_Oferta_Ingenieria_Rev_VFF.pdf.

CSIRO. "Minerals Down Under National Research Flagship". En http://www. csiro.au/org/MDU-Overview.html.

_ (2010). "Peak Minerals in Australia: A Review of Changing Impacts and Benefits".

De Gregorio, J. (2008). "El Ajuste en Chile al Precio del Cobre y Desafíos en la Actual Crisis Crediticia Internacional". Presentación preparada para el X Workshop in International Economics and Finance.

Delgado, Mercedes, Michael E. Porter, Scott Stern (2010). "Clusters, Convergence, and Economic Performance”. En http://papers.ssrn.com/ sol3/papers.cfm?abstract id $=1695011$.

Ffrench Davis, R. y E. Tironi (1974). El Cobre en el Desarrollo Nacional. Ceplan y Universidad Católica. 
Fundacion Chile (2011). Fuerza laboral en la gran minería chilena diagnóstico y recomendaciones, 2011-2020. En http://www.consejominero.cl/doc_ home/Fuerza_Laboral_Diagnostico_y_desafios 12 _ene.pdf.

Global Utmaning and Raw Materials Group (2009). "Mining for Development". http://www.globalutmaning.se/upl/files/9299.pdf.

Goldin, C. (2000). "The Human Capital Century and American Leadership: Virtues of the Past". Economic History Association Presidential Adress 2000. NBER working Paper 8239.

Hartwich, John M. (1977). "Intergenerational Equity and the Investing of Rents from Exhaustible Resources". The American Economic Review, Vol. 67, $\mathrm{N}^{\mathrm{o}} 5$.

Institute for Sustainable Futures University of Technology, Sydney y Department of Civil Engineering Monash University (2010). "Peak minerals in Australia: A review of changing impacts and benefits". En http://www.csiro.au/files/files/pzmt.pdf.

Innova-Corfo (2009). Estudio de identificación de oportunidades para la industria de tecnologías de informacion y comunicaciones en el cluster minero.

Ketels, Christian H. M. (2003). "The Development of the Cluster Concept: Present Experiences and Further Developments". En http://www.isc. hbs.edu/pdf/Frontiers_of_Cluster_Research_2003.11.23.pdf.

Lagos, Gustavo y Edgar Blanco (2010). "Mining and Development in the Region of Antofagasta". Resources Policy, 35.

LaNauze, Robert y Paul Greenhill (2009). "Using Our Research Lead to Stay Ahead". ATSE Focus.

Mac Millanand y M. E. Porter (1990). The Competitive Advantage of Nations. New York: Free Press.

Mason, L., A. Lederwasch, J. Prior et al. (2011): "Vision 2040: Mining, Minerals and Innovation, A Vision for Australia's Mineral Future". Preparado para el documento de CSIRO "Minerals Down Under National Research Flagship", Institute for Sustainable Futures y Curtin University.

Marín Vicuña, Santiago (1935). Nuestros Ingenieros. Santiago: Nascimento.

Marshall, Alfred (1920). Principles of Economics. London: Mc Millan, edición revisada.

May, Jim (2006). "Innovation in the Mineral Industry". ATSE Focus.

Meller, P. (2002). Dilemas y Debates en torno al Cobre. Santiago: Dolmen.

Meller, P. y M. Lima (2003). “Análisis y evaluación de un cluster minero en Chile". Consejo Minero.

Minerals Council of Australia (2009). “Australia 2030, Vision 2020 Project: The Australian Minerals Industry's Infrastructure Path to Prosperity".

Minerals Industry National Skills Shortages Strategy (NSSS) (2006). "Staffing the Supercycle: Labour Force Outlook in the Minerals Sector, 2005 to 2015". Mining for Development a preparatory study May 2009. En http://www.bergforsk.se/research.htm.

Mining Industry Human Resources (MiHR) (agosto 2009). "Ontario Labour Market Demand Projections Mining Industry Workforce Information Network". Prsentado en la Ontario Mining Association. 
National Mining Association (1998a). "The Future Begins with Mining. A Vision of the Mining Industry". En http://www1.eere.energy.gov/ industry/mining/pdfs/vision.pdf.

- (1998b). "Mining Industry Roadmap for Crosscutting Technologies of the Future". En http:/www1.eere.energy.gov/industry/mining/pdfs/ ccroadmap.pdf.

OECD (2005). "Knowledge Intensive Service Activities in the Mining Technology Services Industry in Australia". En http://www.oecd.org/ dataoecd/11/41/34570991.pdf)

(2007). "Reviews of Innovation Policy Chile".

Peterson, D., T. LaTourrette y J. Bartis (2001). "New Forces at Work in Mining: Industry Views of Critical Technologies". RAND Corporation. En http://www.rand.org/pubs/monograph_reports/MR1324.

Porter. M. E. (1998). "Clusters and the New Economies of Competition". Harvard Business Review, Nov.-Dec. 1998.

Ramos, J. (1998). "Una Estrategia de Desarrollo a Partir de los Complejos Productivos en Torno a los Recursos Naturales". Revista de la Cepal $\mathrm{N}^{\mathrm{o}} 66$, diciembre.

(1999). "Una Estrategia de Desarrollo a Partir de los Complejos Productivos (clusters) en Torno a los Recursos Naturales ¿Una Estrategia Prometedora?". Cepal.

The Mining Association of Canada Mineral Production and Community Economic Development (2005). "The Way Forward. A Brief to the 62nd Annual Mines Minister's Conference" - PowerPoint Presentation St Andrews.

Tilton J. y H. Landsber (1997). "Innovation, Productivity Growth, and the Survival of the U.S. Copper Industry". Disussion Paper 97-41, Resources for the Future, Washington, D.C.

Universidad Católica, Dictuc y Centro de Minería (2007). “Caracterización de las empresas proveedoras de la minería y sus capacidades de innovación". En http://www.corfo.cl/rps_corfo_v57/OpenSite/Corfo/ Centro\%20de\%20Documentaci\%C3\%B3n/Estudios/Estudios_doc/ Informe_Final_Proyecto_INNOVA_DICTUC01.pdf. [Una síntesis en Gustavo Lagos (ed.), Innovación y Minería. Ediciones Universidad Católica de Chile.]

Urzúa, O. (2007). "Emergence and Development of Knowledge-Intensive Mining Services (KIMS)". Unctad report.

Velasco A., A. Arenas, J. Rodríguez, M. Jorratt y C. Gamboni (2010). "El Enfoque de Balance Estructural en la Política Fiscal en Chile: Resultados, Metodología y Aplicación al Período 2006-2009”. Estudios de Finanzas Públicas $\mathrm{N}^{\circ} 15$, Dipres, Ministerio de Hacienda, Chile.

World Bank (2008). "Chile Towards a Cohesive and Well Governed National Innovation System".

Wright, G. y J. Czelusta (2002). Exorcizing the Resource Curse: Minerals as a Knowledge Industry, Past and Present. Stanford University. 